BMJ Paediatrics Open

\section{How can general paediatric training be optimised in highly specialised tertiary settings? Twelve tips from an interview- based study of trainees}

Amina Al-Yassin, ${ }^{1}$ Andrew Long, ${ }^{2}$ Sanjiv Sharma, ${ }^{1}$ Joanne May ${ }^{1}$
To cite: Al-Yassin A, Long A, Sharma $S$, et al. How can general paediatric training be optimised in highly specialised tertiary settings? Twelve tips from an interviewbased study of trainees. BMJ Paediatrics Open 2017;1:e000101. doi:10.1136/ bmjpo-2017-000101

- Additional material is published online only. To view please visit the journal online (http://dx.doi.org/10.1136/ bmjpo-2017-000101).

Received 25 May 2017 Revised 7 August 2017 Accepted 9 August 2017
CrossMark

\section{${ }^{1}$ Department Postgraduate} Medical Education, Great Ormond Street Hospital For Children NHS Trust, London, UK ${ }^{2}$ Department of General Paediatrics, Great Ormond Street Hospital For Children NHS Trust, London, UK

\section{Correspondence to} Dr Amina Al-Yassin; amina. al-yassin@nhs.net, aminaalyassin@hotmail.com

\section{ABSTRACT}

Objectives Both general and subspecialty paediatric trainees undertake attachments in highly specialised tertiary hospitals. Trainee feedback suggests that mismatches in expectations between trainees and supervisors and a perceived lack of educational opportunities may lead to trainee dissatisfaction in such settings. With the 'Shape of Training' review (reshaping postgraduate training in the UK to focus on more general themes), this issue is likely to become more apparent. We wished to explore the factors that contribute to a positive educational environment and training experience and identify how this may be improved in highly specialised settings.

Methods General paediatric trainees working at all levels in subspecialty teams at a tertiary hospital were recruited $(n=12)$. Semistructured interviews were undertaken to explore the strengths and weaknesses of training in such a setting and how this could be optimised. Appreciative inquiry methodology was used to identify areas of perceived best practice and consider how these could be promoted and disseminated.

Results Twelve best practice themes were identified: (1) managing expectations by acknowledging the challenges; (2) educational contracting to identify learning needs and opportunities; (3) creative educational supervision; (4) centralised teaching events; (5) signposting learning opportunities; (6) curriculum-mapped pan-hospital teaching programmes; (7) local faculty groups with trainee representation; (8) interprofessional learning; (9) pastoral support systems; (10) crossover weeks to increase clinical exposure; (11) adequate clinical supervision; and (12) rota design to include teaching and clinic time.

Conclusions Tertiary settings have strengths, as well as challenges, for general paediatric training. Twelve trainee-generated tips have been identified to capitalise on the educational potential within these settings. Trainee feedback is essential to diagnose and improve educational environments and appreciative inquiry is a useful tool for this purpose.

\section{INTRODUCTION}

In the UK paediatric trainees undertake 5-8 years of training across three levels ${ }^{1}$ as shown in figure 1 . Levels 1 and 2 training

\section{What is already known on this topic?}

The educational environment is a key component of effective learning at postgraduate levels.

- In highly specialised tertiary hospitals, mismatches in expectations between trainees and supervisors and a perceived lack of educational opportunities may lead to trainee dissatisfaction.

- The 'Shape of Training' review will lead to a greater focus on generalist training and rotations.

\section{What this study hopes to add?}

The study suggests 12 trainee-generated ideas to optimise training in a tertiary centre and divides these into trainee, trainer and organisational factors.

- Suggestions include the use of educational contracting, effective educational supervision, pastoral support systems and signposted educational activities.

- This study identifies components of the educational environment that are valued by trainees, including interprofessional learning.

are in general paediatrics, neonatology and community paediatrics. Level 3 trainees can choose to either subspecialise or continue in general paediatric training. Trainees at all levels may undertake attachments in tertiarylevel hospitals for part of their training and are expected to achieve general paediatric competencies during this time.

Local training surveys have indicated that trainees in such settings may experience dissatisfaction, mismatched trainee-trainer expectations and a perceived lack of educational opportunities. ${ }^{2}$ This study examines the challenges faced by general paediatric trainees (GPTs) undertaking rotational placements in highly specialised settings and how the training experience and educational environment may be optimised. 


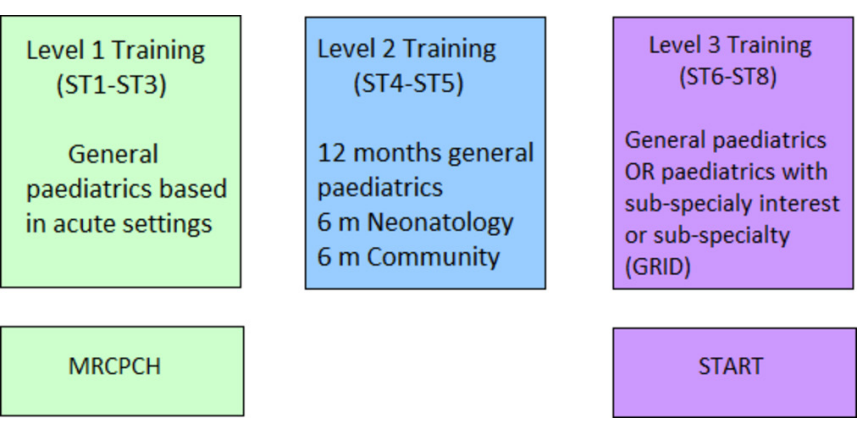

Figure 1 The structure of postgraduate paediatric training in the UK (Royal College of Paediatrics and Child Health (RCPCH) 2017). ${ }^{1} \mathrm{MRCPCH}$, membership of the Royal College of Paediatrics and Child Health; ST, specialty trainee;

The educational environment is recognised as a key component of effective learning. It consists of the physical environment, opportunities, trainee and teacher attitudes, sociocultural and emotional aspects of learning that take place there. ${ }^{3}$ It contributes towards the 'hidden curriculum' through attitudes and role-modelled behaviour that are passed onto learners. ${ }^{4}$ Other key components of the educational environment including communicative teams, role-modelling, relationships, reduced hierarchy and the ability to discuss mistakes. ${ }^{5}{ }^{6}$ In July 2015, the General Medical Council (GMC) published 'Promoting excellence: standards for medical education' ${ }^{7}$ in which they emphasised the importance of institutions' learning environment and culture. The GMC is emphatic that having an 'effective learning culture' enables learners to meet curriculum and training goals and optimise their training.

The most widely used questionnaire-based instruments for measuring educational environments are the Dundee Ready Educational Environment Measure ${ }^{8}$, its postgraduate counterpart the Postgraduate Hospital Educational Environment Measure (PHEEM) ${ }^{9}$ and the newer Scan of Postgraduate Educational Environment Domains (SPEED) tool. ${ }^{10}$ These are validated, widely used, self-administered questionnaires that have been cited in over 90 papers internationally and have high reliability scores. However, their simplicity and feasibility may compromise the depth of their responses, and their psychometric properties are not as reproducible as first intended. ${ }^{3}$

The current tools to measure educational environments have limitations, and there is a lack of literature that focuses on the trainee perspectives. Furthermore,

\section{Objective of this study}

Using appreciative inquiry methodology and semistructured interviews, we aim to explore the following questions:

- How can we best deliver high-quality general paediatric training in tertiary training settings?

- What can we learn from the experiences of the trainees currently undertaking such placements about the strengths, challenges and opportunities of training in this environment? generalist training in paediatrics is likely to become increasingly popular with the Shape of Training review ${ }^{11}$ and discussions about making general paediatric a subspecialty in its own right. The experiences of GPTs are therefore an important and interesting area to study. This study aims to understand the factors that contribute to high-quality educational environments and training experiences for GPTs in a tertiary setting, using appreciative inquiry and semistructured interviews to explore the issues and generate suggestions on how this can be optimised.

\section{METHODS}

\section{Data collection method}

Semistructured interviews were used to collect the data. These were chosen over questionnaires or the readymade tools as they enable richer responses and allow participants to use their own terms of reference, rather than being preframed by the researcher. ${ }^{12}$ Interviews were chosen in preference to focus groups to provide a greater level of confidentiality, prevent pressure to conform to 'normative disclosures', ${ }^{13}$ and due to rota and shift-working, it was more feasible to coordinate to meet with one person rather than a group. The interviewer was a paediatric trainee who has undertaken qualitative research training as part of a higher degree in medical education. The interviews took place in the tertiary hospital setting and were between 20 and 40 minutes in length.

\section{Theoretical perspectives and guiding principles}

The methodology was informed by grounded theory, ${ }^{14}$ and an inductive approach was taken to data interpretation enabling hypotheses to be generated from the responses given. This allowed for themes to emerge organically rather than being influenced by pre-existing ideas. The semistructured interview permitted us to set structure to the interview, while ensuring that participants had flexibility and the freedom to set the agenda. ${ }^{15}$

\section{Sampling method}

Participants were identified from a list provided by the local training provider. Total population sampling was used, and all GPTs at the study hospital were invited to participate through emails and recruitment posters. Subspecialty trainees and non-training grades were excluded. Interviews were undertaken with all the GPTs who volunteered.

\section{Interviewing strategy}

The interviewing strategy and design was inspired by appreciative inquiry (AI) pioneered by Cooperrider and Whitney. ${ }^{16}$ This is a strength-based model that aims to 'understand the organization's potential strengths by looking at an organisation's good experiences and its potential'. ${ }^{16}$ It consists of a cycle with four processes: (1) discover: identifying good practice; (2) dream: envision 
what would work well in the future; (3) design interventions; and (4) deploy: implementation. Trainees were asked to describe the strengths and challenges of their training experience in the tertiary setting. They were asked to identify any areas of current best practice or to make suggestions for improvement. The interview guide is included in online supplementary file 1.

\section{Data analysis}

The interviews were audio-recorded and transcribed. The qualitative data from the interviews was thematically analysed, using open-coding and axial-coding, ensuring that constant comparisons were made to the results to reduce the chance of codes being missed. The codes were then integrated into themes and the themes were arrainged into categories and finally a theoretical framework. $^{1217}$

\section{RESULTS}

Twelve of 37 GPTs were interviewed. These were 9/13 Senior House Officers (ST1-ST3 training years) and 3/24 registrars (ST4-ST8) from a variety of departments. The small number of registrars in the study is acknowledged as a limitation. This may be due to time demands on senior trainees as well as the fact that most senior trainees are subspecialty trainees who was not the targeted population. Results that are very specific to the study hospital have been removed, as they limit the anonymity and generalisability of the results.

\section{Strengths of training}

Participants identified many strengths of training in a specialist setting. These included the sense that these settings were often special, with unique opportunities and interesting patients. Many felt that the settings enabled them to explore subspecialty career options; one trainee had received mentoring for subspecialty applications from her consultant and another had changed her choice of subspecialty as a result of her good experience. A common theme identified was that trainees felt they understood the workings of tertiary hospitals better, which would enable them to make more appropriate referrals in the future. Working in tertiary hospitals also enabled trainees to manage patients at the ceilings of care and those with multiple comorbidities and complex or life-limiting conditions.

Participants felt that the hospital had many educational strengths (see table 1) including team-based teaching, access to internal courses including with affiliated institutions, multidisciplinary team meetings, specialist clinics, procedural skills and the ability to get involved in research projects and to learn from working with other specialised teams.

\section{Weaknesses of training}

Participants mentioned many challenges associated with working in a specialised hospital setting (see table 2).
Some mentioned that there was a mismatch in the expectations of trainees and trainers, especially when it came to specialty-specific knowledge. Some felt that these were high-stakes attachments and had often been specifically chosen by trainees for particular purposes (eg, in order to have access to research opportunities or to explore a subspecialty career option), but this was not always recognised or supported.

A common theme was that the specialised level of care, and complex patient cases, meant that trainees had less of an opportunity to get involved in making decisions about patients or for 'stepping up' in their roles. In some cases, this meant trainees were involved in what was perceived as more administrative tasks or service provision rather than learning or training.

There was a feeling that different specialist teams worked very independently of each other ('in silos'), and therefore trainees did not always benefit from working with and learning from other specialties.

\section{Suggestions for improvement}

The main focus of the interviews was in exploring the ways that the training experience and educational environment can be improved. These are summarised in table 3. Suggestions included preparation for the attachment to align trainee-trainer expectations and setting clear educational objectives. The majority of participants mentioned that they would like to see a pan-hospital teaching programme in order to focus on general competencies and learn from other specialties. They suggested ways to optimise existing learning opportunities, for example, dedicated teaching clinics, opportunity to do research projects and potentially shadowing or cross-covering in other specialties. The need for feedback collection mechanisms was mentioned, and the importance of pastoral support was also emphasised. As part of the AI process, trainees identified sources of current good practice including team-based teaching, allocated time for workplace-based assessments and interprofessional learning within the hospital community of practice.

\section{DISCUSSION \\ Principle findings}

The training experiences of our participants were very heterogeneous; however, the emerging narrative is that specialised hospitals are special places with unique opportunities including career development, educational opportunities and interesting patients. However, they can have challenges including limited clinical autonomy, mismatched trainee-trainer expectations and siloed team working.

The participants highlighted common themes about the way their educational environments and training experience could be improved, and many of the suggestions are generalisable for postgraduate medical training as a whole. The suggestions from trainees can be 
Table 1 A summary of the main themes regarding the positive aspects of training in a tertiary setting

\begin{tabular}{|c|c|c|}
\hline Theme & Subthemes & Example quotes from interviewees \\
\hline \multirow[t]{3}{*}{$\begin{array}{l}\text { Enable trainees to learn more about the } \\
\text { tertiary centres }\end{array}$} & $\begin{array}{l}\text { Managing complex patients, including } \\
\text { those who have reached their ceiling } \\
\text { of care }\end{array}$ & \multirow{3}{*}{$\begin{array}{l}\text { 'It is about producing doctors who can } \\
\text { deliver healthcare and if you want a gooo } \\
\text { doctor who knows what they are talking } \\
\text { about in a DGH you need to expose } \\
\text { them to tertiary care otherwise their } \\
\text { ceiling of knowledge will be capped and } \\
\text { they will flood the tertiary system with } \\
\text { referrals'. (Participant } 1(\mathrm{P} 1) \text { ) }\end{array}$} \\
\hline & $\begin{array}{l}\text { Better understanding of district } \\
\text { general-tertiary hospital dynamics }\end{array}$ & \\
\hline & $\begin{array}{l}\text { Increased confidence in making } \\
\text { referrals to tertiary hospitals in the } \\
\text { future }\end{array}$ & \\
\hline
\end{tabular}

Tertiary hospitals offer many learning Managing complex or sick patients

Attending courses, for example, at related university or academic

'You gain lots of useful skills like practical applicable skills and what happens on the other side of a retrieval'. (P2) institutions

Can often be the 'general paediatrician' for the team

Presenting in large meetings, for example, multidisciplinary or cross-site meetings

\begin{tabular}{|c|c|c|}
\hline Unique opportunity & $\begin{array}{l}\text { Feels like a special place to be/will not } \\
\text { see the same elsewhere } \\
\text { Interesting patients }\end{array}$ & $\begin{array}{l}\text { 'There are so many specialities here } \\
\text { on the ward and things you won't see } \\
\text { anywhere else in the UK. It can be } \\
\text { overwhelming'. (P3) } \\
\text { 'It is a unique and funny place to work. } \\
\text { It is so subspecialised with extreme and } \\
\text { unique pathology. I think it important to } \\
\text { experience'. (P1) }\end{array}$ \\
\hline Opportunity for career exploration & $\begin{array}{l}\text { Deciding if you want to do a } \\
\text { subspecialty job }\end{array}$ & $\begin{array}{l}\text { 'I wasn't considering this speciality until } \\
\text { I came here. I have managed to do so } \\
\text { much for example, national conference, } \\
\text { become an APLS instructor, audits'. (P2) }\end{array}$ \\
\hline Other strengths & $\begin{array}{l}\text { Good team atmosphere } \\
\text { Working with other specialties }\end{array}$ & $\begin{array}{l}\text { 'It's great having the other specialities } \\
\text { around to discuss with or when there is } \\
\text { overlap or diagnostic uncertainty'. (P6) }\end{array}$ \\
\hline
\end{tabular}

categorised as trainee, trainer and organisational factors (table 4).

Trainee factors include ensuring that a personal development plan or 'educational contract' is discussed with the educational supervisor at the start of the attachment. This is a 'negotiated agreement addressing the needs, expectations, roles, and content of an attachment'. ${ }^{18}$ It enables the challenges and opportunities of the placement to be openly discussed and planned for. This can help reduce trainee-trainer mismatch in expectations and may facilitate a deeper more collaborative relationship. As a result of the work of the 'Junior doctors committee', this idea has been introduced to the study hospital in the form of a 'work schedule'. This is a document that sets out the educational component of each post in an individualised way, after agreement between the trainee and educational supervisor. This intervention has recently been introduced and is yet to be evaluated but is hoped that it will enable trainee-trainer expectations to be more closely matched and educational opportunities to be more clearly outlined.

Trainer factors are important in contributing to the educational experience in a specialised attachment. This may necessitate the development of creative models of educational supervision, for example, longer relationships with a supervisor enabling longitudinal continuity of supervision across different rotations, or educational supervisors who are outside the direct clinical 
Table 2 A summary of the main themes regarding the challenges of training in a tertiary setting

\begin{tabular}{|c|c|c|}
\hline Theme & Subthemes & Example quotes from interviewees \\
\hline $\begin{array}{l}\text { Mismatch of expectations } \\
\text { between trainees and trainers }\end{array}$ & $\begin{array}{l}\text { Expectations of baseline knowledge/ } \\
\text { feeling stupid } \\
\text { High stakes attachment/chose all } 3 \text { years for } \\
\text { this } \\
\text { Important to want to come here }\end{array}$ & $\begin{array}{l}\text { 'I think when people are really senior it can be } \\
\text { difficult remembering what it's like when you } \\
\text { have never heard about (these very complex) } \\
\text { conditions'. (Participant (P) 3) }\end{array}$ \\
\hline $\begin{array}{l}\text { Very specialised care means } \\
\text { less opportunity for trainees }\end{array}$ & $\begin{array}{l}\text { Reduced opportunity for step-up/taking a } \\
\text { step backwards } \\
\text { Not enough involvement in sick children } \\
\text { Very specialised care }\end{array}$ & $\begin{array}{l}\text { 'For those about to become registrars they } \\
\text { can't step up as it's specialised'. (P7) } \\
\text { 'The workload is very high and I feel stupid } \\
\text { asking basic questions as they are on a much } \\
\text { higher level. Lots of the cases are too complex } \\
\text { for us to deal with so it's mostly senior led'. } \\
\text { (P8) }\end{array}$ \\
\hline $\begin{array}{l}\text { Pastoral care not always } \\
\text { prioritised }\end{array}$ & Anonymity in training/not nurtured & $\begin{array}{l}\text { 'Consultants see you as a nameless faceless } \\
\text { SHO'. (P9) }\end{array}$ \\
\hline Culture of learning not universal & Culture/ethos of learning & $\begin{array}{l}\text { 'As an institution it sometimes feels too big to } \\
\text { train or teach'. (P2) }\end{array}$ \\
\hline Other & $\begin{array}{l}\text { Differentiation between specialist and } \\
\text { generalist trainees } \\
\text { Tick box educational supervision } \\
\text { Difficult to get involved in projects } \\
\text { Practical issues, for example, busy job and } \\
\text { rota issues }\end{array}$ & $\begin{array}{l}\text { 'It is hard work when you are doing lots of the } \\
\text { service provision and other people are getting } \\
\text { the training opportunities'. (P6) } \\
\text { 'There is a lot of learning through diffusion } \\
\text { and osmosis but it is hard...everyone is so } \\
\text { stretched for time'. (P1) }\end{array}$ \\
\hline
\end{tabular}

team enabling a broader educational agenda to be set. The trainees also mentioned the importance of robust feedback collection mechanisms. The $\mathrm{GMC}^{7}$ requires all educational departments to have local faculty group meetings in which trainee progress is reviewed and workforce issues and unfulfilled training requirements identified and actioned early. Pastoral support was highlighted as requiring improvement. Pantaleoni et $a l^{19}$ found that paediatric residents had significant increase in burnout as training progresses and that preventative strategies are required. This could be through proactive educational supervision, psychological support for trainees, or promotion of deanery-based mentoring schemes.

Organisational factors are fundamental to the establishment of a positive educational environment. These can include ensuring that regular, protected teaching sessions are arranged for trainees. Specialised hospitals are often affiliated to universities or scientific institutions, many of which will have an active educational programme. Centralising these events and signposting them as opportunities to trainees may improve the perceived culture of teaching and learning. Interprofessional learning was also identified as an area of good practice. Members of the multiprofessional team often have enhanced specialist skills and knowledge and some may formally take on advanced roles (eg, advanced practitioners). They are a rich source of knowledge and learning within the community of practice in these specialist settings. Interprofessional or multidisciplinary education can contribute to 'better team dynamics, more holistic approach to patients and an improvement in knowledge and skills when it comes to complex conditions'. 20

Not all trainees may enjoy, benefit from or be suited to highly specialised rotations. There is a need for continued close collaboration between hospital educational leaders and training programme directors to best select and prepare trainees for these posts so that there can be the best match between expectations and training needs.

\section{Comparison with existing literature}

The findings of our study were compared with those of the PHEEM $^{9}$ and SPEED $^{10}$ studies, which are currently the most widely used measures of the quality of educational environments (table 5).

\section{Implications at our institution}

As a result of trainee feedback from this study and others, our institution has started a regular cross-specialty study afternoon, with specialists from the hospital delivering curriculum-mapped teaching. The sessions are open to trainees from outside of the hospital too and have received positive feedback. The postgraduate medical education department has also developed a smartphone 
Table 3 A summary of the suggestions for improvement

\begin{tabular}{|c|c|c|}
\hline Theme & Subthemes & Example quotes from interviewees \\
\hline $\begin{array}{l}\text { Trainees and trainers preparing } \\
\text { for the attachment }\end{array}$ & $\begin{array}{l}\text { Adapting attachment to trainees learning } \\
\text { needs and personal development goals } \\
\text { Trainees taking more proactive } \\
\text { approach to learning } \\
\text { Ensuring trainees prepared for (and } \\
\text { suitable for) this type of attachment }\end{array}$ & $\begin{array}{l}\text { 'It's about picking a few bits and pieces that you } \\
\text { would be able to use rather than being an expert } \\
\text { at the end of it. Having a conversation with the } \\
\text { consultant in the beginning to set your objectives'. } \\
\text { (Participant (P) 1) } \\
\text { 'You need to have realistic expectations... it is a } \\
\text { different experience so make the most of it but it's } \\
\text { not everyone's cup of tea'. (P7) }\end{array}$ \\
\hline Improving learning opportunities & $\begin{array}{l}\text { Making more use of specialist resources } \\
\text { and other teams } \\
\text { More structured teaching/ } \\
\text { general teaching programme } \\
\text { Rota including clinic } \\
\text { Bedside teaching }\end{array}$ & $\begin{array}{l}\text { 'For the world centre of excellence I would have } \\
\text { expected to be taught by world specialists in } \\
\text { different areas'. (P9) }\end{array}$ \\
\hline Improving pastoral support & Mentoring or pastoral support & $\begin{array}{l}\text { 'There is no senior that looks out for your career } \\
\text { progression and wellbeing. Paeds training is so } \\
\text { long and takes a massive toll on your life and it } \\
\text { would be nice if there was someone who cared... } \\
\text { it would make a massive difference'. (P7) }\end{array}$ \\
\hline Improving feedback & $\begin{array}{l}\text { Better feedback from seniors } \\
\text { Junior-junior or junior-senior meetings } \\
\text { or local faculty groups }\end{array}$ & $\begin{array}{l}\text { 'We have an anonymised feedback box and } \\
\text { reflective practice every week in small groups for } \\
\text { psychological and pastoral support'. (P2) }\end{array}$ \\
\hline Other & $\begin{array}{l}\text { More access to audit, project } \\
\text { opportunities } \\
\text { Interprofessional learning } \\
\text { Creating educational supervision, } \\
\text { for example, Longer spanning } \\
\text { supervisors or supervisors from other } \\
\text { specialties }\end{array}$ & $\begin{array}{l}\text { 'General paed consultants as educational } \\
\text { supervisors for the general paediatricians because } \\
\text { they could bring up things that you wouldn't have } \\
\text { thought of' (P2) }\end{array}$ \\
\hline
\end{tabular}

application where all teaching opportunities (across departments and in different affiliated institutions) are advertised and timetabled, enabling trainees to access a wide-range of learning. All educational supervisors have been accredited, and local faculty groups have been set up with trainee representation.

Many of our 'twelve tips' can be implemented through restructuring of current practice, enabling changes to be

Table 4 Factors perceived by trainees to enhance an educational environment: trainee, trainer and organisational factors

\section{Factors contributing to a successful educational environment}

Trainee factors

Trainer factors

Organisational factors
(1) Manage expectations by acknowledging and addressing the challenges early

(2) Use educational contracting to identify learning needs, expectations and opportunities

(3) Creative, proactive educational supervision

(4) Effective local faculty groups with trainee representation

(5) Develop systems for pastoral support

(6) Adequate clinical supervision

(7) Rota design to include teaching and clinic time

(8) Curriculum-mapped protected pan-hospital teaching programme

(9) Centralise teaching events

(10) Signpost learning opportunities including non-clinical

(11) Interprofessional learning

(12) Crossover or shadowing weeks to increase clinical exposure 
Table 5 Factors contributing to the nature of the educational environment: themes identified in our study, compared with those identified from previous studies-PHEEM ${ }^{9}$ and SPEED ${ }^{10}$ studies

\begin{tabular}{ll}
\hline Identified in our study and previous studies & Identified in our study but not in previous studies \\
\hline Career preparation & Interprofessional learning \\
\hline Clinical and practical skills & Mismatch of expectations \\
\hline Formal education programme & Special/unique place to work \\
\hline Learning opportunities seized & Cross-specialty working \\
\hline Handover & Setting educational objectives \\
\hline Feedback from supervisors & Balance between training/service \\
\hline Autonomy & Reputation \\
\hline Appropriate levels of clinical responsibility & Culture \\
\hline Interprofessional working & Opportunity to step-up/make decisions \\
\hline Study leave & Mentoring \\
\hline Accessibility of seniors & Flexibility in rota \\
Attendance at teaching is protected & \\
Pastoral support & \\
Workload & \\
Induction & \\
\hline
\end{tabular}

made without significant time or resource implications. For example, most hospitals have a wide range of educational opportunities on offer, but the signposting of these could be made more explicit. Similarly, regular educational supervision meetings are a compulsory part of training; however, using educational contracting can help to structure this relationship. The GMC is committed to improving educational supervisor's and skills attainment and making sure that funding (including supporting professional activities time) is available for them to fulfil their role. Annual appraisal of educational supervisors is an important tool to support supervisors in reviewing their activities and ensuring that they adopt best practice.

\section{Implications to clinicians and policymakers}

We hope that the 12 tips, and the trainee/trainer/organisation model, will be useful tools in designing and evaluating rotational placements for GPTs in tertiary settings as well as postgraduate training placements more generally. We hope that the study will promote the use of AI as a tool in the evaluation of complex learning environments. This study is a reminder that trainee buy-in and feedback are essential in order to evaluate and improve training programmes.

\section{Strengths and weaknesses of the study}

The strength of this study was that it was an in-depth interview-based study, which resulted in 12 actionable points to improve the educational experience for paediatric trainees. This study has added to our understanding of what is important to trainees in their educational environments.

There are limitations to the applicability of the findings including the fact that this study was undertaken solely on paediatric trainees and in a unique highly specialised setting. The study included a relatively smaller number of senior trainees (ST4-8). GPTs at all levels have similar curriculum competencies to acquire, in terms of knowledge, communication and procedural skills. However, more senior trainees may require more opportunities for independent clinical decision making, team-leading and management competencies, and these aspects may therefore have not been fully explored due to the low participation from senior trainees.

The limitations of this study relate to the theory of contextualism, in which it is accepted that 'knowledge emerges from different contexts and also reflects the researcher's position so it is always local, situated and provisional ${ }^{21}$; therefore, wide applicability is not always a realistic outcome.

Contributors $A A$ and $A L$ designed the work. AA conducted the literature review and the semistructured interviews. AA and AL were both involved in analysing the results of the data. AA drafted the first version of the manuscript, and AL revised and approved the final version. JM contributed to project conceptualisation and design, advised on data collection methods and was involved in critical revision of the article and approval of the final version to be submitted. SS contributed to project conceptualisation including defining the research question and was involved in critical revision of the article and approval of the final version to be submitted.

Competing interests None declared.

Ethics approval Ethical approval was obtained both from UCL and from the study hospital.

Provenance and peer review Not commissioned; externally peer reviewed.

Open Access This is an Open Access article distributed in accordance with the Creative Commons Attribution Non Commercial (CC BY-NC 4.0) license, which permits others to distribute, remix, adapt, build upon this work non-commercially, and license their derivative works on different terms, provided the original work is properly cited and the use is non-commercial. See: http://creativecommons.org/ licenses/by-nc/4.0/

(C) Article author(s) (or their employer(s) unless otherwise stated in the text of the article) 2017. All rights reserved. No commercial use is permitted unless otherwise expressly granted. 


\section{REFERENCES}

1. RCPCH. General paediatrics training. http://www.rcpch.ac.uk/ training-examinations-professional-development/postgraduatetraining/general-paediatrics-training/ge (accessed 18 Apr 2017).

2. Pillai A, Lamb K, Wallace M, et al . From the coalface: report of junior doctor perspectives on training in Great Ormond Street Hospital; 2013.

3. Isba R. Creating the learning environment. In: Oxford textbook of medical education. Oxford, UK: Oxford University Press, 2013.

4. Hafferty FW. Beyond curriculum reform: confronting medicine's hidden curriculum. Acad Med 1998;73:403-7.

5. Iblher P, Hofmann M, Zupanic M, et al. What motivates young physicians? - a qualitative analysis of the learning climate in specialist medical training. BMC Med Educ 2015;15:176.

6 Bandura A, Walters RH. Social learning theory. Oxford, England: Prentice-Hall, 1977.

7 General Medical Council. 2015. Promoting excellence: standards for medical education and training. 978-0-901458-20-4.

8. Roff S, McAleer S, Harden RM, et al. Development and validation of the Dundee Ready Education Environment Measure (DREEM). Med Teach 1997;19:295-9.

9. Roff S, McAleer S, Skinner A. Development and validation of an instrument to measure the postgraduate clinical learning and teaching educational environment for hospital-based junior doctors in the UK. Med Teach 2005;27:326-31.

10. Schönrock-Adema J, Visscher M, Raat AN, et al. Development and validation of the Scan of Postgraduate Educational Environment
Domains (SPEED): a brief instrument to assess the educational environment in postgraduate medical education. PLoS One 2015;10:e0137872.

11. Greenaway D. Shape of training: securing the future of excellent patient care(Final report of the independent review); 2013

12. Braun V, Clarke V. Successful qualitative research: a practical guide for beginners. California, United States: Sage Publications, 2013.

13. Smithson J. Using and analysing focus groups: limitations and possibilities. Int J Soc Res Methodol 2000;3:103-19.

14. Glaser B, Strauss A. The discovery of grounded theory. . London: Weidenfeld and Nicholson, 1967:Vol. 24. 288-304.

15. Cohen D, Crabtree B. Qualitative research guidelines project. 2006. http://www.qualres.org/

16. Cooperrider DL, Whitney D. A positive revolution in change: Appreciative inquiry. Publ Admin Publ Pol 2001;87:611-30.

17. Charmaz K. Constructivist and objectivist grounded theory. In: Handbook of qualitative research. , 2000:Vol. 2, 509-35.

18. Pratt D, Magill MK. Educational contracts: a basis for effective clinical teaching. J Med Educ 1983;58:462-7.

19. Pantaleoni JL, Augustine EM, Sourkes BM, et al. Burnout in pediatric residents over a 2-year period: a longitudinal study. Acad Pediatr 2014;14:167-72.

20 Bromage A. Interprofessional E-Learning and Collaborative Work: Practices and Technologies: Practices and Technologies. USA: IGI Global., 2010.

21. Madill A, Jordan A, Shirley C. Objectivity and reliability in qualitative analysis: realist, contextualist and radical constructionist epistemologies. Br J Psychol 2000;91:1-20. 